The answer to these three key questions will differ in the short term (using existing capacity) and the long term (potential for expanding capacity); but if current fees are greater than the marginal cost of enrolling more students, this strategy makes economic sense. The fact that so few systems around the world are choosing this strategy in the face of much more painful choices may mean that officials determined that quality would be compromised and/or marginal costs are higher than current fees. Or it may be that institutional rigidities, lack of a fundamental understanding of marginal costs, or political considerations led to decisions that were unjustifiable on the economics.

Institutional or system officials obviously must decide how to respond to government cutbacks in funds based on their own set of conditions. However, the potential benefits of increasing cost-recovery rates by adding numbers of students rather than, or in addition to, raising tuition fees should be an important consideration in their decision making.

\section{Impact of the Financial Crisis on Higher Education in the United States}

\section{ROger L. GeIger}

Roger L. Geiger is distinguished professor of higher education at Pennsylvania State University.E-mail: rlgo@psu.edu.

$\mathrm{T}$ he economic crisis of 2008-2009 brought precipitous declines in almost all classes of financial assets and a contraction of economic activity that was, for a time, compared with the Great Depression. Colleges and universities were forced to adjust to a variety of shortfalls in anticipated revenues, but deeper structural changes were virtually impossible. Now, midway into the 2009-2010 academic year, longer-term perspectives, rather than panicky predictions, are possible. In the short term, conditions have not proved to be as bad as feared; but the current crisis has made it far more difficult to address the long-term weaknesses of American higher education.

\section{ENDOWMENT}

The wealthiest colleges and universities, normally immune to the tempests besetting other institutions, suffered significant financial damage in this crisis. With all classes of financial assets plunging, their diversified portfolios of alternative investments were hit from all directions. The losses of 2008-2009 will be felt for years to come, and many institu- tions have announced permanent budget reductions of Io percent. Cuts of this magnitude can only be achieved by firing people, since salaries comprise roughly three-quarters of university expenditures. Institutions have also instituted hiring freezes and cancelled building plans. Still, these "hardships" should be put in perspective.

The wealthiest colleges and universities, normally immune to the tempests besetting other institutions, suffered significant financial damage in this crisis.

The fall in endowment values had the greatest impact on the wealthiest institutions, since they support a larger share of their budgets with endowment income. Before 2008, these same institutions had experienced the greatest prosperity of their storied histories as a result of the investment booms of the late I990s and 2003-2007. Their prosperity induced considerable extravagance, especially in amenities for undergraduates. However, these institutions also uphold the highest standards of US science, scholarship, and graduate education. To date, the possible compromise or decline in these areas has not been revealed, although future investments are another matter. Harvard, for example, has placed plans for its new science campus on hold. Stanford will not fill 50 open faculty positions and also halted construction projects. Thus, the research capacity of the nation's most distinguished universities will be frozen for some time.

Still, the immediate picture has brightened somewhat. The stabilization of financial markets, the apparent end of the "official" recession in the United States, and some recovery in US and international financial markets all promise some mitigation of the downturn. Still, selective private colleges and universities have become more dependent on student tuition.

\section{The States and Public Support for Higher Education}

One higher education official lamented: "every source of revenue coming into the state has decreased." States, unlike the federal government, must cover their expenditures with revenues, and that has meant rescissions (taking back funds already appropriated) and reductions in higher education appropriations. In six states, rescissions during FY(fiscal year) 2009 took back from 8 to 24 percent of state funds. But everyone knew that allocations for FY20Io would be disastrous, although as it turns out, they were not quite that bad. The Obama stimulus package contained over $\$ 50$ billion to replace state cuts in education funding, including higher education.

Public universities in many states have faced severe cuts in appropriations. California, with the largest and most admired system of public higher education-and a dysfunctional legis- 
lature- has been the poster child for the Great Recession. The University of California, the Cal State university system, and the community colleges all suffered 20 percent cuts in state funding. Other states experiencing decreases of similar magnitudes include Washington, Hawaii, Arizona, and South Carolina-all places where the state has provided the majority of funding for public higher education. Cuts of this size are unprecedented and can only be accommodated by diminishing quality and/or services.

Recession economics teaches that a revival of state tax revenues is virtually the last element in a recovery. States will face further budgetary squeezes next year. Unfortunately, many of the stopgap measures or budget gimmicks used to cope with this year's crisis will be impossible to duplicate. Also missing will be stimulus funds, which many states chose to expend in full for FY2OIO in order to soften the blow. Hence, shortfalls for FY2OII promise to be even more severe.

\section{2}

One higher education official lamented: "every source of revenue coming into the state has decreased."

Public universities in virtually every state have resorted to substantial increases in student tuition. As these hikes do help to buttress revenues, this trend is good news, at least for university budgets. However, public tuitions have been rising steeply, especially since 2000 . Increases of 9 to io percent for $2009 /$ Io will increase public tuitions by around $\$ 400$ to $\$ 500$. California will add another 30 percent hike. More students will require larger student loans to meet these fees.

States have been underinvesting in their colleges and universities for many years. Disinvestment has been most evident at the multitude of regional public colleges and universities that provide open access to perhaps one-half of four-year college students. The same can be said of community colleges, which enroll one-third of postsecondary students. Hence, the compromises and sacrifices being made this year and next are superimposed onto years of retrenchment.

\section{Enrollment Patterns}

The economic downturn has caused students to downgrade their educational aspirations and educational spending. Thus, students have opted for public universities instead of private ones, for regional institutions instead of flagships, for two-year instead of four-year, for commuting instead of attending a residential college. This race to lower costs has increased demand for places at regional public universities and community colleges at a time when their resources are being reduced. In California the response has been to limit enrollment. By one estimate, the three systems will reduce enrollments by 300,000 (or I5 percent) by 20II, with most of this attrition occurring at community colleges. However, nationally, com- munity college enrollments jumped substantially in fall, 2009 . That sector is particularly well suited to serve financially strapped or career-minded students. The Obama administration has emphasized this role by proposing a special appropriation for community colleges, although such federal funds would be small compared with cuts in state appropriations.

\section{Longer-Term Consequences}

US universities are recognized for excellence in all aspects of academic research and graduate education. Yet, American higher education has a far more equivocal record in recent years for educating young people in keeping with a knowledge society and a democratic polity. The United States no longer leads the world in the proportion of young people graduating from college, as it did until late in the 2 oth century.

Selective colleges and universities have been able to raise their prices consistently more than the cost of living (consumer price index $+3 \%$ annually, since I980) because demand rose as they increased quality. The availability of financial aid and the practice of differential pricing (tuition discounting) made this strategy far more effective than it could have been in isolation. These practices simultaneously broadened the market for high-quality education (increasing demand) and bolstered quality as well by ensuring the recruitment of top students. A likely decrease in overall demand for high-cost, selective colleges could destabilize this model. The endowment losses suffered by these institutions have translated into long-

Recession economics teaches that a revival of state tax revenues is virtually the last element in a recovery. States will face further budgetary squeezes next year.

term budget cuts. These institutions, particularly the not-quiteso-wealthy institutions, will be looking to raise more revenue from student tuition, which means granting less student aid. At the same time, less-wealthy students will be leaving the applicant pool, but not the wealthiest. Anecdotal evidence has already reported a perceptible shift from merit to ability to pay in 2009 admissions. Thus, the student clientele of the selective sector, already skewed heavily toward the affluent, is likely to become more socially elite-and less elite intellectually.

In the open sector of higher education, the lack of financial resources weighs down completion rates and extends time-todegree. High prices have a demonstrable impact, particularly for students from the two lowest-income quintiles. They are more reluctant to take on debt and have resorted to growing amounts of part-time work. Institutions in this sector must accommodate students with weaker academic preparation. Most likely, these last two factors interact, as large classes, parttime teachers, and unavailable classes take the greatest toll on 
weaker students. The majority of American college students are probably affected to some extent by these conditions. Unfortunately, these market conditions also seem to feed upon themselves, largely through the disinvestment in public higher education and the steep stratification in the effectiveness of precollege education.

A comparison of college participation rates in Organization for Economic Cooperation and Development countries found that educational expansion was reducing the discrepancy between the highest and lowest income groups everywhere except in the United States. Here, college attendance by the wealthy has actually increased more since I980 than gains among low-income groups. Furthermore, attendance at selective college and universities is more socially skewed, and graduation from college is still more socially skewed. Before I980, American higher education, on balance, consistently provided opportunities for social and economic advancement, but since that date it appears, on balance, to be generating social reproduction.

\section{A likely decrease in overall demand for high-cost, selective colleges could destabilize this model. The endowment losses suffered by these institutions have translated into long-term budget cuts.}

\section{CONCLUSION}

The economic downturn of 2008-2009 will exaggerate the fundamental problems facing American higher education and make them more difficult to address, let alone reverse or attenuate. The downward ratchet in attendance decisions will make the selective sector more socially exclusive. Conversely, enrollment pressures at open-access institutions, even while public funds to support those institutions are being withdrawn, seem destined to compromise quality.

Academic research and graduate education have endured the crisis better than other sectors, but here the danger lies in the not-too-distant future. The most distinguished universities, which largely support scientific excellence, have ceased to expand their research capacity, and this strategy has ominous implications. Federal research funding has been artificially inflated with stimulus funds. This has buoyed academic research for the current year or two, but cutbacks almost certainly lie in the future. If public support for research declines in the way public support for higher education has, the future will indeed be bleak.

\section{The Competition for International Postsecondary Education Students}

\section{Madeleine F. Green and Kimberly Koch}

Madeleine F. Green is vice president for international initiatives at the American Council on Education. E-mail: Madelein_Green@ace.nche.edu. Kimberley Koch is former ACE program associate. A longer version of this article is available at

<http://www.acenet.edu/Content/NavigationMenu/ProgramsServices/cii /pubs/ace/SizingUptheCompetition_Septemberog.pdfs.

In 2007, there were an estimated 2.8 million internationally 1 mobile students, up from I.8 million in I999. Those numbers are expected to continue to increase. The global marketplace for internationally mobile students has led nations to compete with one another by developing a variety of policies and strategies to attract these students. This article highlights the goals and recruitment efforts made by the top five destination countries, in order of their share of the international student population.

\section{United States}

The United States continues to be the world's leading higher education destination. Nearly 672,000 international students studied in the United States in 2008/09. The vast majority of these students come from Asia. Since 2002, India has sent the highest number of students to the United States, followed by China, South Korea, and Japan.

In the United States, the majority of recruitment efforts are conducted by individual institutions. Unlike other countries, the United States has no coordinated national strategy or targets. At the national level, the US Department of State's Bureau of Educational and Cultural Affairs sponsors EducationUSA, a network of professional educational advisers and education information centers that promotes US higher education worldwide and offers international students information on the application process, admissions requirements, potential scholarship funding, visas, and everyday living in the United States. EducationUSA maintains a Web site, produces brochures in six languages, and operates 450 advising centers around the world. Additionally, the bureau funds overseas regional and national educational advising coordinators to organize conferences and adviser training and serve as a resource on national and regional trends.

Institutions compete with each other to attract international students. Some colleges and universities partner with other institutions to promote higher education in their state or region. Study Philadelphia, for example, is the result of the 